Rosi Haarer-Becker

Physiotherapeutin,

Verlagsbereichsleiterin Physio- und

Ergotherapie bei Thieme
Uwe Harste

Physiotherapeut,

FiHH das Fortbildungsinstitut in Hamburg

\title{
physiokongress 2013 - Wir freuen uns darauf
}

_ „Muskulatur wäre auch mal ein gutes Thema!“, hörten wir beim diesjährigen physiokongress im Januar von den Teilnehmern. Gut, dachten wir, das nehmen wir, und legten mit der Planung los. Für den physiokongress vom 25.-27. Januar 2013 konnten wir hochkarätige und außergewöhnliche Referenten gewinnen.

_ Die Eröffnung wird unter dem Motto „Was uns stärkt" stehen. Und dies ist nicht nur unsere Muskulatur, sondern auch unser Geist. Professor Dieter Felsenberg wird den Auftakt geben. Er erforscht an der Charité in Berlin die Folgen des Muskel- und Knochenstoffwechsels von Astronauten. Mit Mentaltrainer Thomas Jaklitsch werden wir die Macht mentaler Kräfte erleben. Er hat einen Physiotherapeu-

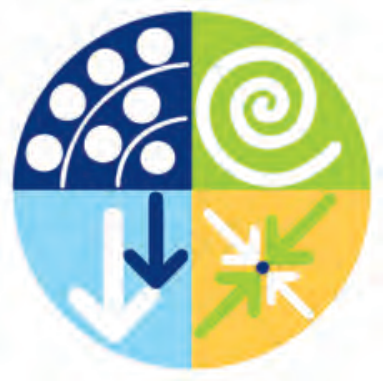
ten und Extremsportler beim „Race Across America“ betreut - eines der härtesten Radrennen der Welt (॰ physiopraxis 6/12).

_ Das sind nur zwei Kostproben von vielen. Weitere stehen auf Seite 12 und im Programmheft, das dieser Ausgabe der physiopraxis beiliegt. Sollten Sie lieber im Internet schmökern, finden Sie unter www.thieme.de/physiokongress ab Oktober nähere Informationen zu den Referenten und ihren Themen.

_ Wir freuen uns, wenn Sie zum physiokongress kommen, und noch mehr, wenn Sie sich vor Ort beteiligen. Wir haben diesmal viel Zeit für Diskussionen eingeplant. Nutzen Sie sie! So können wir nicht nur von der „Bühne“, sondern auch aus dem Plenum lernen.

Herzlichst, Ihre physiokongress-Programmplaner
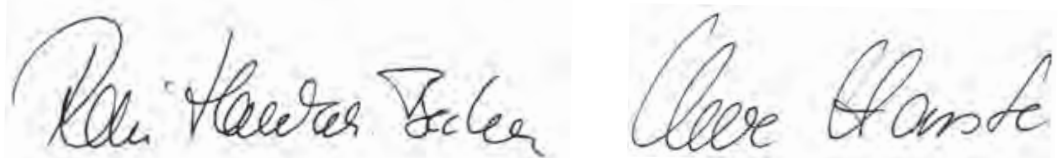

Und das ist 2013 neu: Der physiokongress ist an die neue Fachmesse Therapro angegliedert.

\section{$\operatorname{Ir}=\mathbf{A}=$}

\begin{tabular}{|c|c|}
\hline \multicolumn{2}{|l|}{ ZU GEWINNEN } \\
\hline \multicolumn{2}{|c|}{$\begin{array}{l}\text { In jeder physiopraxis werden attrak- } \\
\text { tive Gewinne verlost. Möchten Sie } \\
\text { einen ergattern, klicken Sie unter } \\
\text { www.thieme.de/physioonline auf } \\
\text { „physiopraxis-exklusiv“. }\end{array}$} \\
\hline \multicolumn{2}{|c|}{$\begin{array}{l}\text { Und das gibt es in dieser Ausgabe zu } \\
\text { gewinnen: }\end{array}$} \\
\hline $\begin{array}{l}\text { Bücher } \\
\text { 1-mal „Klinische Muster“ }\end{array}$ & Seite 36 \\
\hline $\begin{array}{l}\text { 2-mal „Frühphase Schlag- } \\
\text { anfall““ }\end{array}$ & Seite 42 \\
\hline $\begin{array}{l}\text { 3-mal „Wer Schatten } \\
\text { küsst““ }\end{array}$ & Seite 52 \\
\hline 1-mal „Lehren und Lernen & "Seite 58 \\
\hline $\begin{array}{l}\text { und außerdem } \\
1 \text { Dauerkarte für den } \\
\text { physiokongress } 2013\end{array}$ & Seite 12 \\
\hline 1 Jahresabo „neuroreha“ & Seite 12 \\
\hline 10 Apps „Tiltmeter Pro“ & Seite 26 \\
\hline 1 Familientelefon & Seite 62 \\
\hline 3 Antistressknetbälle & Seite 66 \\
\hline
\end{tabular}

